\title{
Clicker Lessons: Assessing and Addressing Student Responses to Audience Response Systems
}

\author{
Tim Pelton, Leslee Francis Pelton, \& Mary Sanseverino \\ University of Victoria
}

This project began in response to a perceived need to assess students' perceptions with respect to the emerging use of audience response systems (clickers) in several mid- to large-size undergraduate courses at the University of Victoria. We developed and validated a "Clicker Use Survey" to gather students' opinions with respect to clicker utility and the impact of clicker use on their learning. With the collected data we generated a set of baseline distributions to support assessment of various clicker use protocols and created a self-evaluation tool to share with instructors to support teacher reflection on the efficacy of their clicker practices. We also provided a sample self-evaluation to model the use of the tool. Links to the survey instrument, baseline data and self-evaluation tool, and sample selfevaluation are provided.

\section{Introduction}

C lassroom communication and interaction are influenced by many factors. In traditional large classes, communication tends to be between the teacher and a few keen and vocal students. The sheer number of students makes it infeasible to hear from every student and the traditional teacher-led question-answer process often fails to promote real discussion. Many students choose to simply listen and passively take notes, relying on others to be the active participants in the class. This silent majority includes students who may remain silent because there are limited opportunities to contribute, lack confidence in their ability to articulate their ideas or questions, or avoid participation for fear of embarrassment or other social constraints (Dickman, 1993; Reynolds \& Nunn, 1997; Pelton \& Francis Pelton, 2003). Many of these students are on the verge of a teachable moment - with connections ready to be made, misunderstandings ready to be challenged, or interesting, unpopular or politically incorrect opinions needing to be discussed. By remaining silent, the students forfeit opportunities to learn and deny similar opportunities to their classmates who may not be ready to articulate similar questions, ideas or concerns. 
Reviewing existing research shows that techniques that promote and support student participation yield students who pay more attention in class, use in-depth thinking and reflection, learn from one another's reasoning and mistakes, evaluate their own misconceptions, perform better on tests, have greater retention, and have improved attitudes toward learning (Francis Pelton \& Pelton, 2006). Audience response systems (also known as 'clickers') were created to increase participation and engagement of audience members in large presentation halls or classrooms where traditional teaching conditions might not support much interaction. The systems allow the instructor to present prepared or ad-hoc questions and response options to students and permit them to select and anonymously submit their responses through a wireless 'clicker' (typically radio frequency, but older systems also may use infra-red). Student responses are captured and processed in the instructor's laptop. The resulting distribution can then be presented graphically to the class via a data projector to support assessment, discussions, group activities, etc. Replacing or supplementing the traditional lecture and note-taking classes (passive learning) with this type of interactive process appears to support learning by increasing productive communication of processes, understandings and ideas and encouraging student engagement (Horowitz, 1988; Burnstein \& Lederman, 2001; Guthrie \& Carlin, 2004; Pelton and Francis Pelton, 2003; Pelton $\&$ Francis Pelton, 2006).

\section{The Project}

The apparent benefits of using clickers in a classroom have encouraged both individual instructors and institutions of higher education to introduce them in courses. This naturally leads instructors to question how their use of clickers impacts student learning. This project was designed by existing clicker users to help to more formally assess students' attitudes towards the use of clickers in several mid to large size undergraduate courses. We developed and validated a "Clicker Use Survey" to assess students' perceptions of clicker utility and the impact of clicker use on their learning and learning related behaviours, and published a collection of baseline distributions for the survey questions to support teacher self evaluation.

\section{The study context}

We collected data from 11 different mid- to largeenrollment undergraduate courses at the University of Victoria that were using clickers in their classes in the current year. Classes ranged in size from 40 students to over 200 students. Classes covered a wide range of subjects, mainly in the sciences and social sciences (anatomy, anthropology, astronomy, chemistry, computer science, geography, mathematics, and psychology).

Two different audience response systems were used in the classes surveyed - the CPS (Classroom Performance System) by eInstruction and the iClicker. These systems were selected because they both used radio frequency communications (previous experience had suggested that infra-red systems were not suitable for most large classroom situations) and they supported at least two operating systems (an important feature when seeking to make a campus wide recommendation).

The eInstruction system had advantages with respect to included functionality but these advantages were tempered by a higher threshold (more time and effort required to learn) and friction (more time required to transform lessons and initiate use in classrooms) as well as a higher cost or fee structure. The iClicker system was easier to set up and use, the costs were lower, and the software necessary to use the tool is open source (this potential for community based enhancement and customization was appealing to many instructors).

Some instructors chose to assign marks to clicker use - either for participation or performance. Other instructors were only interested in using student responses to support student engagement in classroom activities and assess student understanding of the topics, and so, did not track individual participation. Originally we hoped that there might be some potential to examine the impact of the differences in response systems and differences in participation tracking on student perception of clicker utility, but other factors obscured the effects. 


\section{Methodology}

The Clicker Use Survey shown in Figure 1 includes questions on several demographic variables (gender, number of university courses completed, percentage of classes attended, and frequency of bringing the clicker to class), followed by 18 Likert type items assessing attitudes toward clickers and clicker utility. Students were also invited to make comments on anything pertaining to the clickers. These comments were explicitly encouraged in the verbal instructions given as the surveys were being distributed and again in print form on the bottom of the survey. The consent form also included a request to compare response patterns to student grades.

The authors and participating instructors (all somewhat familiar with audience response technology) devised the items in the questionnaire to cover the apparent issues associated with the use of clickers in the classroom. The development process was guided by informal classroom feedback, student evaluations, an analysis of comments made on an anonymous online forum (Slashdot, 2005), and experiences associated with the introduction and evaluation of other educational technologies. The instrument was piloted, item response distributions were assessed for functioning and suitability and minor revisions were made prior to administration to all classes. No attempt was made to control or influence the instructors' adoption or use of clickers in their classroom - leaving several variables unmanaged - but also providing a more authentic view into the issues surrounding the adoption of such devices.

The responses were tallied for each of the levels in each Likert question in the survey. The order of the responses was reversed in negatively worded items to facilitate cross item comparisons. A cumulative 'score' or scale is not presented here because although we believe that we are examining evidence to support the validation of the instrument and the underlying latent construct (i.e., perceived clicker utility in the classroom), we do not believe that we have sufficient data to justify the assumption that all of the items would load perfectly onto a single scale or that values generated would fall on a linear scale.
The following sections provide a short summary of the observed response distributions and a qualitative analysis and interpretation along with the results of a simple factor analysis (suspending our concerns about the aggregation of non-linear likert data). We also present a tool (Pelton, Sanseverino, \& Francis Pelton, 2007) to support instructors wishing to apply the "Clicker Use Survey" to qualitatively evaluate the efficacy and utility of clickers in their classes. Future papers will examine relationships between demographics, grades, and student responses (both Likert and open-ended).

\section{Results}

The Clicker Use Survey was presented to the 11 classes at the end of their respective terms in an 8 month period. Informal observations suggested that more than $90 \%$ of the students attending classes on the days that the survey was administered consented to the study and completed the questionnaire. A total of 1107 questionnaires were completed, representing approximately $70 \%$ of the students enrolled in the participating first- and second-year classes.

Four conditions were anticipated to affect student assessment of clicker use. The teaching style was expected to have a substantial effect and while we cannot control this effect, it is hoped that the baseline distributions resulting from this research will allow instructors to self-evaluate the response distributions from their classes in juxtaposition to a 'typical' response distribution. A second expected influence on perceived utility is the use of grades or marks to encourage or coerce students into purchasing (if necessary), registering, and using the clickers in the classroom. Third, the specific system used was expected to have a minor effect on student perception of response systems because of the differences in registration, daily setup, and fluidity. And finally we anticipated that there would be a negative effect on perceived clicker use if the students were required to purchase their own clicker units. However, once the data was collected and the conditions in the classrooms examined we found that all of the classes that used the tracked model, and all of the classes that offloaded equipment costs to students, used the eInstruction system. 


\section{Figure 1 \\ Clicker Use Survey}

\section{Clicker Use Survey}

To evaluate the effectiveness of clickers, it is necessary to ask for honest responses from students using the devices. Your co-operation is very much appreciated. Your responses are confidential and only anonymous comments and aggregate results will be disclosed.

Student ID:

Check One: $\quad$ Male

Female

How many units $(1$ course $=1.5$ units $)$ of University level courses have you taken (including this term)?

What percentage of classes in this course did you attend?

$0-25 \%$

$26-50 \%$

$51-75 \%$

$76-100 \%$

How often did you bring the clicker to class:

Never

Sometimes

Most of the time

Always

Please respond to each question by circling one number from 1 to 5 . Strongly Disagree

Disagree Undecided use the clickers.

1

12

2

3

3

Strongly
Agree

2. When we use the clickers my participation increases in other ways too.

3. I found the use of clickers to be distracting and unhelpful.

1

2

3

4

5

I feel uncomfortable sharing my responses via the clickers.

5. Learning with clickers improves my understanding of the course content.

$\begin{array}{ll}1 & 2\end{array}$

2

3

$4 \quad 5$

1

12

3

4

5

6. Learning with the clickers gives me confidence to ask more questions.

7. Using the clickers encourages me to spend more time preparing for class.

1

8. Using clickers encourages me to attend more classes.

9. Using the clickers promotes more focused discussion during class.

1

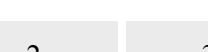

3

$4 \quad 5$

$2+3$

\begin{tabular}{|l|l|}
\hline 1 & 2 \\
\hline 1 & 2 \\
\hline
\end{tabular}

10. I would like to use the clickers in other courses.

11. The graphs provided by the clicker system are useful.

1

12. I benefit by seeing how other students respond to a question.

13. Using the clickers in class is too time consuming.

1

23

$3 \quad 4$

4

14. I would do better in this class without the clickers.

15. I had difficulties getting my clicker to work in class.

1

23

$3 \quad 4$

$4 \quad 5$

6. I would have liked to use the clickers more often in class.

17. At first, learning with the clickers was enjoyable but later I was bored.

\begin{tabular}{|l|l|}
\hline 1 \\
\hline 1
\end{tabular}

23

3

4

5

1

$2 \quad 3$

3

4

$4 \quad 5$

\begin{tabular}{l|l|l}
3 & 4 & 5
\end{tabular}

8. Using the clickers helped to better prepare me for quizzes and exams.

\begin{tabular}{|l|l|l|l|l|}
\hline 1 & 2 & 3 & 4 & 5 \\
\hline 1 & 2 & 3 & 4 & 5 \\
\hline 1 & 2 & 3 & 4 & 5 \\
\hline
\end{tabular}

Please write any comments you would like to make on the back of this form. 
In addition, it was observed that the instructors using the tracked model tended to have fewer years of teaching experience. Thus, three of our conditions were confounded and so the data does not support a full exploration of all of our intended comparisons of conditions. However, the aggregated response distributions for the survey questions were still perceived as useful both for the validation of our instrument and as a baseline of perceived clicker utility to identify trends examine interventions and support selfevaluation.

To provide an example of the results collected from the survey, a selection of class distributions, as well as a baseline distribution (all students) for question \#16, "I would have liked to use the clickers more often in class," is presented in Figure 2. In the baseline distribution (all students, front, light blue bars), we see that across all classes, the students were generally content with the level of clicker use. For some classes (e.g., 1 and 4), the response distribution includes a substantially larger "strongly disagree" component than the baseline. Possible reasons might include, overuse of clicker questions in classroom, the instructors' skill in using clickers in the classroom, or negative grading affected students' desire to use clickers (both of these classes associated grades with clicker use).

Various facets affecting students' perceptions of clicker use can be assessed using the collected data. For example, in Figure 3, we compare response distributions from classes where participation was tracked and marks were associated with clicker use and the other classes that did not link marks to clicker responses or participation. We have reversed all negatively oriented questions to facilitate evaluation and comparison across items -1 indicates a very negative attitude or opinion and a 5 indicates a very positive attitude or opinion. Note that while all tracked classes were using the eInstruction system, both systems were used in untracked classes. In addition, tracked classes tended to have instructors with fewer years of teaching experience. The baseline combines all classes and we see that the student response distributions from the tracked classes were substantially negatively affected. Possible reasons for the observed differences in the distribution include experience of the instruc- tor or negative attitudes in response to tracking participation.

As we reviewed each of the survey item response distributions, we noted that the baseline distribution provided a useful starting point for the evaluation and interpretation of group and individual class results. For some questions, the variation observed across groups or classes was minimal, while for others the class effect was substantial. Other papers examining the distributions of each question and the student comments are in progress.

Some general observations arising from our examination of the response distributions include:

- students generally felt comfortable sharing responses;

- students agreed that seeing the response distributions in class was beneficial;

- class distributions were less positive when marks were associated with clicker use; and

- clicker use did not seem to yield substantial increases in student preparation or confidence to ask questions in class.

These observations were consistent with a cursory review of student comments in connection with the Likert question response patterns.

We began our factor analysis by including all items and found that perhaps two or three factors might be present in the raw data. However upon reflecting on our search for the intended factor of clicker utility we decided to remove questions $4,7,8$, 15 and 18 - as they spoke most directly to other issues such as personal comfort (4), learning habits (7, $8)$, technological struggles (15) and format of class assessments (18). The second factor analysis provided moderate evidence to assert a single factor $(46.8 \%$ of the variance accounted for in the first factor and the screen plot suggested a single factor). This factor analysis evidence in concert with the examination of response distributions, the iterative item construction process using experienced clicker users, the piloting and refining process, and the consistency of observation distributions with classroom observations and classroom descriptions suggests that the Clicker Use 


\section{Figure 2 \\ Selected class distributions for survey question \#16: "I would have liked to use the clickers more often in class."}

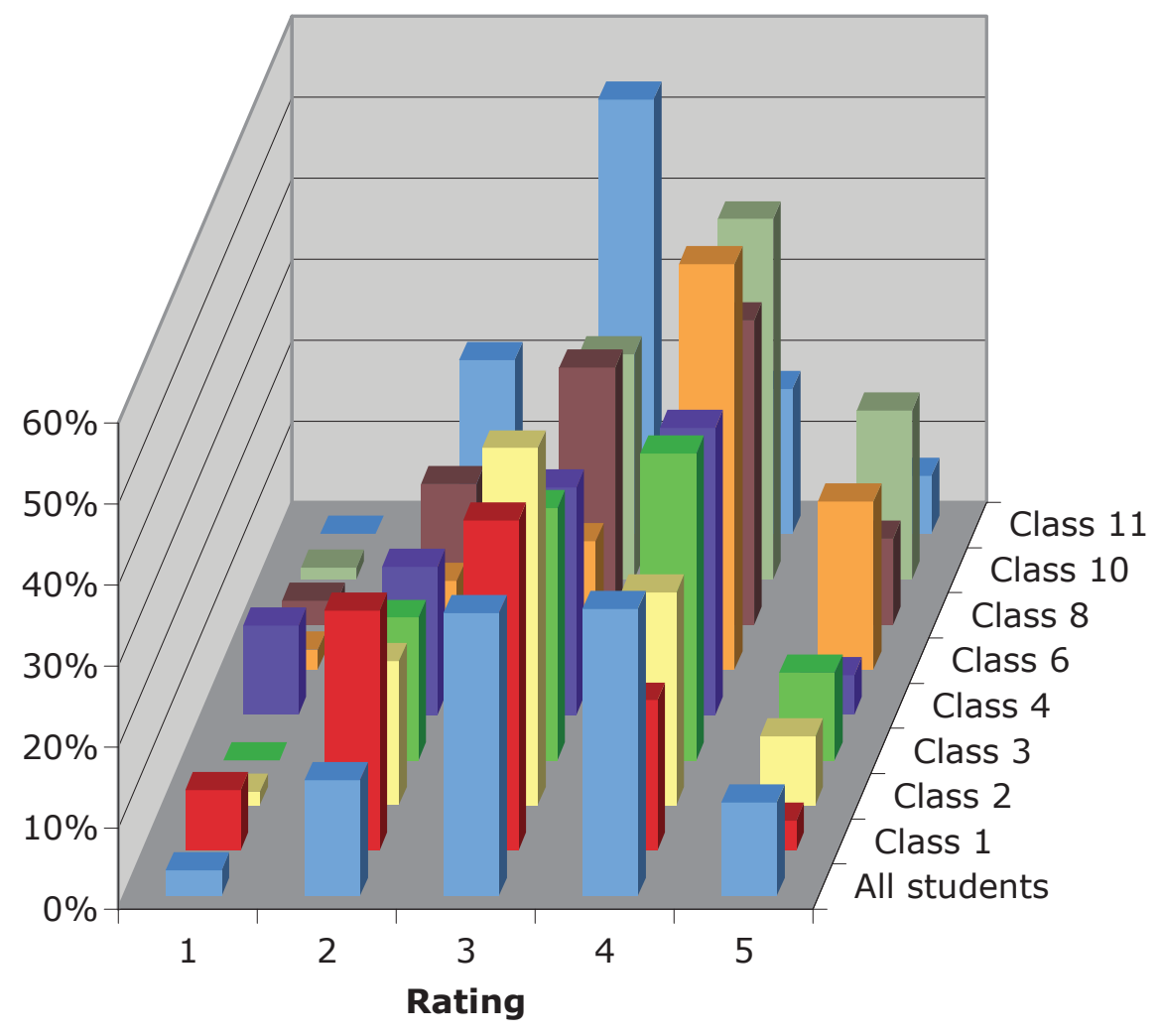

Survey can be used to meaningfully assess the utility of clickers in individual classrooms.

\section{Self Evaluation Tool}

The Clicker Use Survey is freely available to the academic community to support institutional and selfevaluation of classroom clicker use.

The authors have created a self-evaluation tool to support instructors wishing to examine student perceptions of clicker utility as adopted in their own classrooms. This resource has been published in the form of an Excel spreadsheet (Pelton, Francis Pelton, \& Sanseverino, 2007) that contains the baseline survey response distributions for 1107 students along with preset data entry fields for the instructor to enter his/her class response distributions. Comparative distribution graphs are automatically generated once the instructor has entered a set of class data, and these can be copied and used in self-evaluation reports.

Finally, an exemplar self-evaluation report (Francis Pelton \& Pelton, 2007) is provided as a model to help other instructors generate supporting documentation for their own teaching dossiers.

The Clicker Use Survey was designed to assess student perceptions of the use and utility of clickers in the classroom. The items were generated, piloted, refined, and evaluated by instructors familiar with the use of audience response systems. When this response system expertise is combined with the intuitively interpretable baseline data and distributions and the adequate loading of the items on a single factor (given the inherently multifaceted nature of the classroom context), it provides adequate validation evidence to support the practical application of this instrument in assessing the perceived utility of clickers in the classroom, the examination of the relative 


\section{Figure 3}

\section{Tracked vs. untracked distributions for survey question \#14: "I would do better in this class without the clickers."}

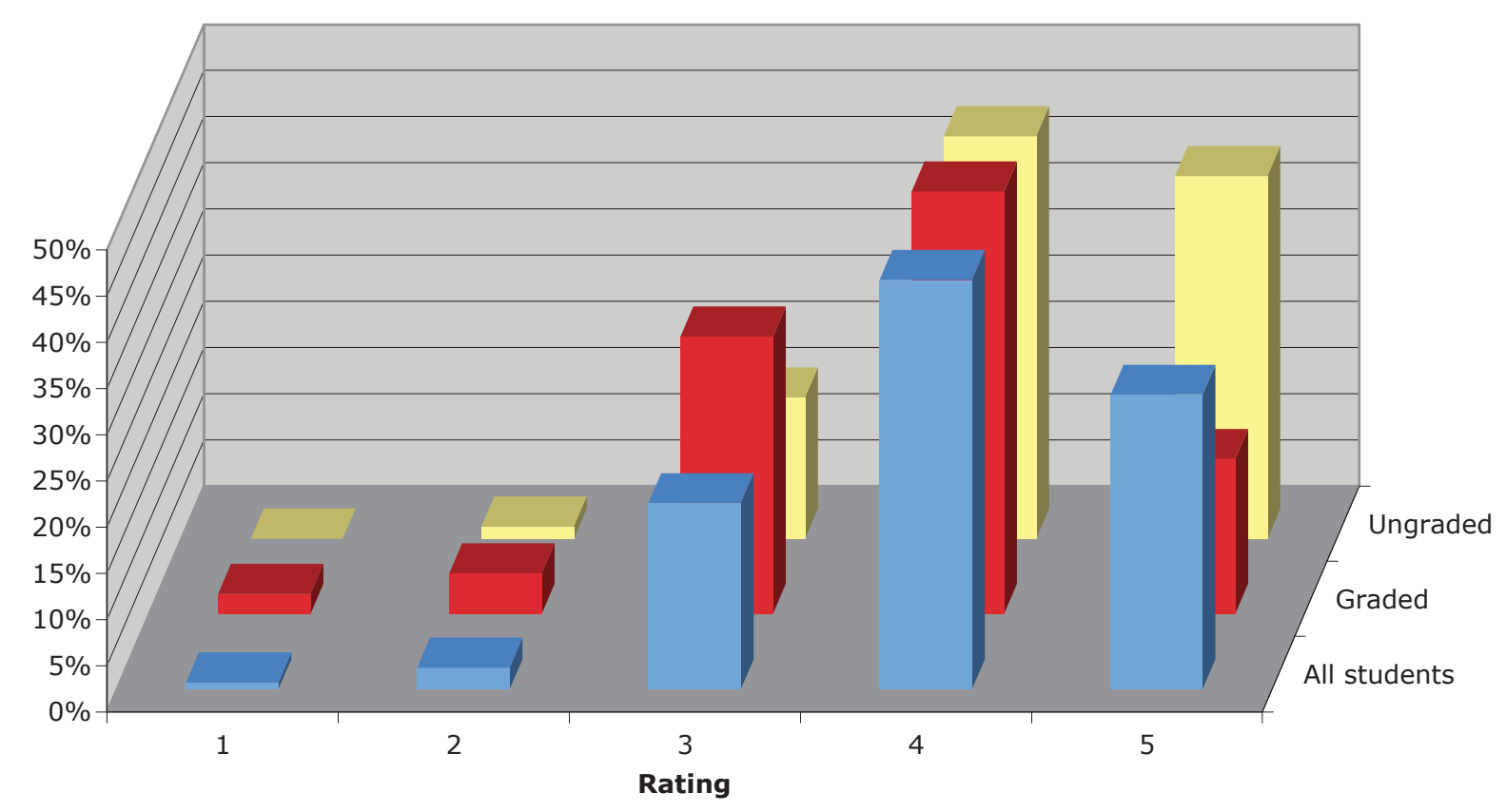

efficacy of various clicker related protocols, and the examination of changes over time in the instructors ability to effectively use clickers in their classroom. The authors welcome comments, queries, and suggestions on this resource from other educators.

\section{References}

Burnstein, R., \& Lederman, L. (2001). Using wireless keypads in lecture classes. The Physics Teacher, 39, 8-11.

Dickman, C. B. (1993). Gender differences and instructional discrimination in the classroom. Journal of Invitational Theory and Practice, 2(1).

Francis Pelton, L. \& Pelton, T. (2006). Selected and constructed response systems in mathematics classrooms. In D. Banks (Ed.), Audience response systems in higher education: Applications and cases (pp. 175-186). Hershey, PA: Idea Group.
Francis Pelton, L. \& Pelton, T. (2007). Example analysis using self evaluation tool. Retrieved May 1, 2008, from http://web.uvic.ca/-tpelton/ ars/math-clicker-analysis.doc

Francis Pelton, L., Pelton, T. \& Sanseverino, M. (2006). Clicker use survey. Retrieved May 1, 2008, from http://web.uvic.ca/ - tpelton/ars/ clicker-use-survey.doc

Guthrie, R., \& Carlin, A. (2004). Waking the dead: Using interactive technology to engage passive listeners in the classroom. Proceedings of the Tenth Americas Conference on Information Systems, New York, NY. Retrieved May 1, 2008, from http:/www.mhhe.com/cps/docs/ CPSWP_WakindDead082003.pdf

Horowitz, H. (1988). Interactivity in a classroom environment. Presented at the Sixth Conference on Interactive Instruction Delivery for the Society of Applied Learning Technology (SALT). Retrieved May 1, 2008, from http://www.op- 
tiontechnologies.com/pdf/classroom_interactivity.pdf

Pelton, T. \& Francis Pelton, L. (2003). The classroom interaction system (cis): Neo-slates for the classroom. Connections '03. Victoria BC. May 2003. Retrieved May 1, 2008, from http:// www.educ.uvic.ca/Research/conferences/ connections2003/06PeltonT102.pdf

Pelton, T. \& Francis Pelton, L. (2006). Creating a constructed response system to support learning. In D. Banks (Ed.), Audience Response Systems in Higher Education: Applications and Cases (pp. 334-346). Hershey, PA: Idea Group.

Pelton, T., Sanseverino, M. \& Francis Pelton, L. (2007). Clicker use self evaluation tool. Retrieved May 1, 2008, from web.uvic. $\mathrm{ca} /$ tpelton/ars/clicker-self-eval.xls

Reynolds, K. C. \& Nunn, C. E. (1997). Engaging classrooms: Student participation and the instructional factors that shape it. Paper presented at the annual meeting of the Association for the Study of Higher Education, Albuquerque, NM. Retrieved May 1, 2008, from http://eric.ed.gov/ERICWebPortal/ recordDetail?accno=ED415815

Slashdot. (2005). Clickers redefining classrooms. Online discussion topic presented at Slashdot. org. Retrieved May 1, 2008 from http:// slashdot.org/article.pl?sid=05/08/06/052421 $0 \&$ from $=$ rss 